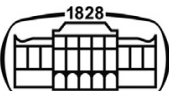

AKADÉMIAI KIADÓ

\title{
Analysis of cold-formed steel rectangular hollow flange beams
}

\author{
Nathalie Eid* ำ and Attila László Joó
}

\section{Pollack Periodica \\ An International Journal for Engineering and Information Sciences}

16 (2021) 1, 58-64

DOI:

$10.1556 / 606.2020 .00110$

(c) 2020 The Author(s)

\section{ORIGINAL RESEARCH} PAPER

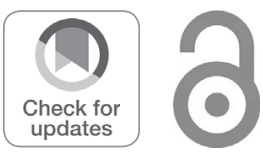

Department of Structural Engineering, Faculty of Civil Engineering, Budapest University of Technology and Economics, Müegyetem rkp. 3, 1111 Budapest, Hungary

Received: November 28, 2019 • Revised manuscript received: April 19, 2020 • Accepted: May 2, 2020 Published online: February 4, 2021

\begin{abstract}
This paper presents the results of a theoretical-numerical study of laterally-restrained thin-walled steel rectangular hollow flange beams subjected to bending, shear and bending and shear interaction. Finite element analyses were carried out by using ANSYS software, and validated by previous experimental tests. Furthermore, the effect of intermediate stiffeners was investigated, where the improvement percentage in bending capacity was $4.4 \%$. Additionally, all the corresponding outcomes were calculated according to EN 1993-1-3. The results showed that current standard rules tend to be somewhat conservative in both bending and bending and shear interaction cases, while they are not quite accurate in shear case.
\end{abstract}

\section{KEYWORDS}

cold-formed steel profiles, rectangular hollow flange beams, flexural capacity, Shear capacity, bending and shear interaction, numerical modeling

\section{INTRODUCTION}

Nowadays, Rectangular Hollow Flange Beams (RHFBs) have been used frequently in structures field. For instance, one of their famous applications is LiteSteel Beam (LSB) (Fig. 1), which is a new cold-formed steel beam produced by Onesteel Australian Tube Mills (OATM), made of two torsionally rigid hollow flanges and a slender web [1].

The study of buckling is important and necessary for the design of any facility, but since cold-formed elements are exposed to more complex buckling patterns than hot-rolled steel elements, hence, buckling analyses has become an essential issue in cold-formed section design. Thus, in the last 10 years many experimental tests and research projects have been performed to improve RHFBs behavior and resistance. Many ways of forming and configurations of cross section were discussed with experimental, numerical and theoretical studies, where buckling behavior and corresponding capacities were observed [2-5]. For example, Jeyaragan and Mahendran [6] showed that LSB segments are prone to many types of collapse when they are exposed to bending, depending on the length of spans. Furthermore, strengthening method of RHFBs have been investigated in many papers, either by using different connecting methods, or web stiffeners and CFRP [7-9].

Since RHFB is a new cross section in cold-formed steel, new structural system will be produced by using these elements. Thus, the design method of Eurocode must be checked for this new system, especially that most of the research projects in this topic is conducted according to the Australian standards. Hence, the objective of this paper is to apply and verify the available design methods of Eurocode of cold-formed section to typical cold-formed steel rectangular hollow flange beams and to improve the capacity of rectangular hollow flange beams by means of intermediate stiffener.

A numerical model using ANSYS software [10] will be verified by previous tests [2] in Section 2. The next step is to check the bending design value according to Eurocode 3 in Section 3 and compare design values from hand calculation $M_{c, R d}^{E C}$, numerical model $M_{c, R d}^{F E M}$ 

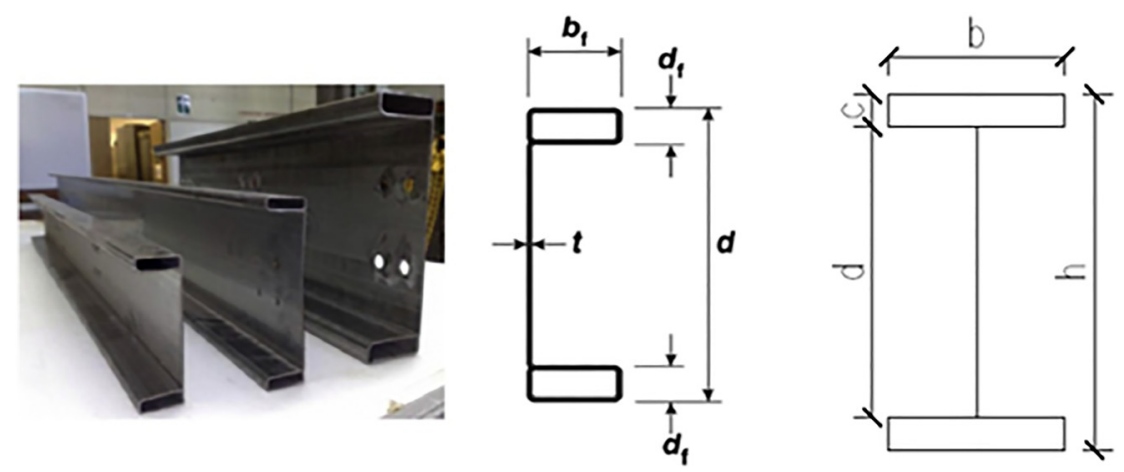

Fig. 1. Left: LiteSteel beams [1], right: Geometry of the tested section, on the basis of [2]

and test results $M_{c, R d}^{\text {Test }}$ together. Furthermore, Section 3 provides details of the improved cross-section analysis by flange intermediate stiffeners, and its bending design values, which are denoted by $M_{c, R d}^{F, E C}, M_{c, R d}^{F, F E M}$, where $F$ refers to flange. In Section 4 the load and boundary conditions of the original numerical model will be modified in order to study shear case instead of pure flexural case. Additionally, the combination between flexural moment and shear will be studied and checked in Section 5. Finally, drawing conclusions and recommendation for future research will be done in Section 6. The previous steps are demonstrated in Table 1.

\section{NUMERICAL MODEL DEVELOPMENT}

A shell finite element model was developed in this section; using ANSYS software; and validated according to test results obtained from previous experimental research at Trento University, Italy [2]. The tests were carried out on full-scale specimens to investigate the flexural performance of cold-formed thin-walled laterally-restrained steel RHFBs.

\subsection{Geometry and material properties}

The beam's span was $4 \mathrm{~m}$, the cross section, which was modeled, is RHFB-300. All specimens were fabricated by welding tubes to web. The averages of the measured dimensions of the specimens, which are illustrated in Table 2 [2], were the geometry of the modeled section (Fig. 1).

The measured yield strength of the flanges is $394.8 \mathrm{MPa}$ and for the web is $258.5 \mathrm{MPa}$, the elastic modulus is $203 \mathrm{GPa}$

Table 1. Detailed research program

\begin{tabular}{lcccc}
\hline \multirow{2}{*}{ Research program } & \multicolumn{3}{c}{ Section types } \\
\cline { 2 - 5 } Internal forces & $\mathrm{M}$ & Test, EC, FEM & EC, FEM & - \\
& $\mathrm{V}$ & EC, FEM & - & EC, FEM \\
& $\mathrm{M}+\mathrm{V}$ & EC, FEM & EC, FEM & - \\
\hline
\end{tabular}

Where $O$ is the original cross section; $F$ is the improved cross section by intermediate stiffeners in the flanges; $W$ is the improved cross section by intermediate stiffener in the web.
[2]. Namely, an elastic-perfectly plastic material model was used here.

\subsection{Finite elements}

4-node element type shell 181 was used in the model each node has six degrees of freedom. The maximum dimension of any element is $25 \mathrm{~mm}$. Since the failure mode of all specimens did not show any kind of separation between web and flanges, the modeling of welding was not considered.

\subsection{Loads and constraints}

In detail, a roller and a hinge were modeled at the supports by assigning the relevant condition to all nodes along each edge of the lower flange. In addition, restraints against horizontal displacement were added along the edge of the upper plate of the top flange. Also, the load was applied by imposing increasing four concentrated loads to the top nodes of web stiffeners, located at half meter from the middle of the span (Fig. 2).

\subsection{Modeling of initial imperfection}

Since the section is restrained against any type of global buckling through boundary conditions, which simulate the real construction; conditions presented by sheathing on both side of section, the observed buckling mode was only local one. The amplitude of the imperfection was selected by following the approach proposed by Schafer and Peköz [11] according to the equation $d=0.006 w$, where $w$ is the element width and $d$ represents the maximum imperfection amplitude. Furthermore, an imperfection sensitivity analysis was carried out, the results shows that using higher imperfection amplitudes than the one, which gives the same ultimate load as in test results gave almost the same ultimate

Table 2. Measured section dimensions of the specimens

\begin{tabular}{lllcc}
\hline & $h(\mathrm{~mm})$ & $b(\mathrm{~mm})$ & $c_{t}(\mathrm{~mm})$ & $t(\mathrm{~mm})$ \\
\hline T04 RHFB-300 & 298.3 & 150 & 30.4 & 2.87 \\
T05 RHFB-300 & 296.8 & 150.1 & 30.0 & 2.86 \\
T05 RHFB-300 & 297.5 & 150.1 & 30.2 & 2.93 \\
F.E. model & 297.53 & 150.067 & 30.2 & 2.887 \\
\hline
\end{tabular}



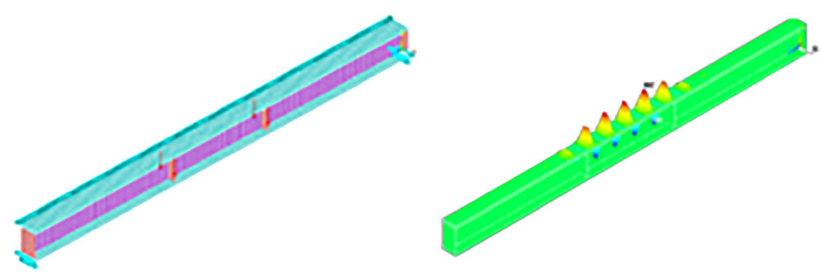

Fig. 2. Left: Applied loads and restraint conditions, right: Lowest local buckling mode shape of the compressed flange

capacity but with difference in the initial stiffness. Figure 2 shows the buckling mode shape of the compressed flange. In detail, the buckling modes were represented by local buckling waves distributed on the top of the compressed flange. The longitudinal wavelength is $180 \mathrm{~mm}$ approximately. Indeed, the main reasons of buckling in RHF profiles are because of the high imperfection amplitude which is resulted by the production process. Thus, developing an exclusive cut machine could reduce the high imperfection problem with good percentage and consequently enhance the section buckling capacity.

\subsection{Analysis type}

The type of analysis is nonlinear, with assumption of using large deformation. The material model is nonlinear as well (Geometrically and Material Nonlinear Imperfection Analysis (GMNIA)). Thus, multiple load steps to solve the problem were needed.

\subsection{Evaluation of the results}

Figure 3 shows a comparison of bending momentdisplacement curves between test [2] and numerical results. The figure shows an apparent convergence between the curves. The ultimate moments of the tested beams are 96.0, 97.30, $94.20 \mathrm{kNm}$ for T04, T05, and T06 respectively [2], while it is $101.37 \mathrm{kNm}$ for the numerical result. In this figure $M_{y, w}, M_{y, f}$ mean average elastic moment for web and flanges respectively, $M_{\mathrm{p}}$ means average plastic moment of the specimens computed based on actual geometric and mechanical properties. Moreover, the mode of failure that

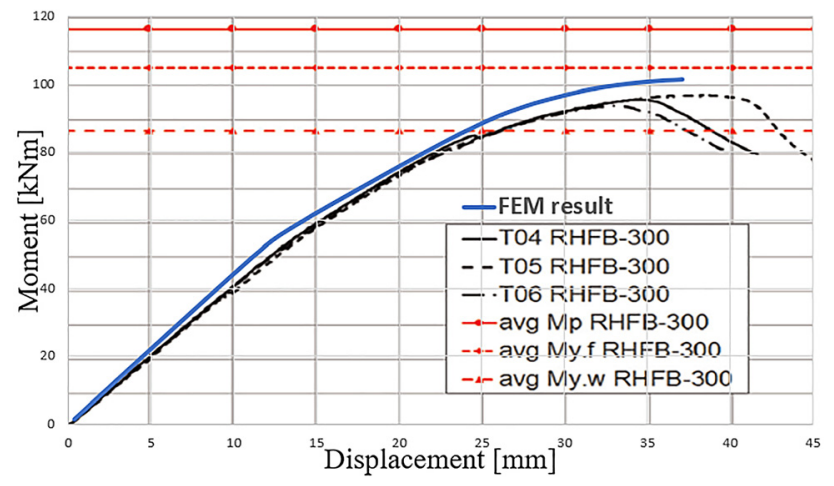

Fig. 3. Experimental [2] and numerical bending momentdisplacement curves

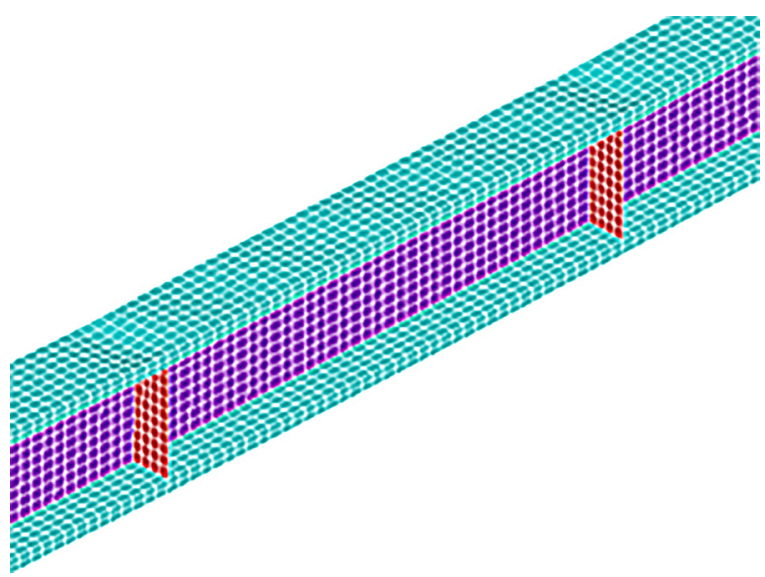

Fig. 4. Failure mode of the beam

demonstrates the main plastic mechanism on the top compressed flange was well captured as it is shown in Fig. 4. As a result, the developed finite element model, which follows the tested beams behavior will be used for further studies.

\section{CROSS-SECTION ANALYSIS AND DEVELOPMENT FOR BENDING MOMENT}

In subsection 3.1 the design value for original section was calculated according to Eurocode (EC 1993-1-3) [12] and test results [2] were converted to design value according to [12] as well. Moreover, a new numerical model has been performed by using nominal properties in order to define the moment capacity design value of the structure. Furthermore, a comparison of the previous design values was made. Finally, analysis of the improved cross section by intermediate stiffeners in the flanges was conducted in subsection 3.2 and comparison between the results was demonstrated in subsection 3.3.

\subsection{Original section}

The effective cross section (Fig. 5) and bending design resistance were determined based on both part 1-3 [12] and part 1-5 [13] of Eurocode 3, by using nominal dimensions
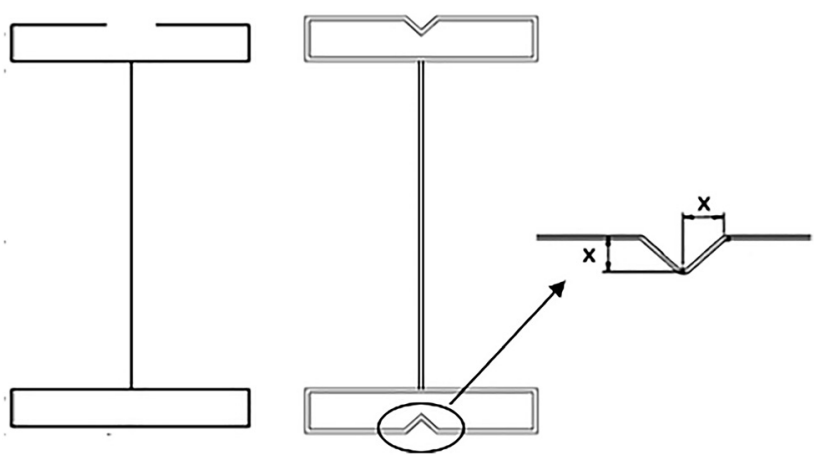

Fig. 5. Left: Effective cross section, right: Improved section by intermediate stiffeners in the flanges 
Table 3. Nominal section dimensions of the specimens [2]

\begin{tabular}{ccccc}
\hline & $h(\mathrm{~mm})$ & $b(\mathrm{~mm})$ & $c_{t}(\mathrm{~mm})$ & $t(\mathrm{~mm})$ \\
\hline RHFB-300 & 300 & 150 & 30 & 3 \\
\hline
\end{tabular}

according to Table 3 and assuming that the basic yield strength of flange tubes is $f_{y b}=355 \mathrm{~N} / \mathrm{mm}^{2}$, the basic yield strength of web plate is $f_{y b}=235 \mathrm{~N} / \mathrm{mm}^{2}$ (nominal values of basic yield strength according to table $3.1 \mathrm{~b}$ in [12] and partial factor $\gamma_{M 0}=1.0$. Hence, the design moment resistance is:

$$
M_{c, R d}^{E C}=\frac{W_{e f f} \times f_{y b}}{\gamma_{M 0}}=91.90 \mathrm{kNm}
$$

To determine the bending design value from FEM, $\left(M_{c, R d}^{F E M}\right)$ the same numerical model, which was discussed in Section 2, was performed but with three differences. The first difference is that the measured values of section dimensions were replaced by nominal values according to Table 3 . The second difference is that the measured values of yield strengths were replaced by nominal values, while the third one is the maximum imperfection amplitude, which was taken according to Eurocode, $\operatorname{imp}=a / 200$ where $a$ is the element width. The maximum moment resistance in this case was $98.27 \mathrm{kNm}$.

In order to compare test results with $M_{c, R d}^{E C}$ and $M_{c, R d}^{F E M}$, the design value of test results $M_{c, R d}^{\text {Test }}$ was calculated according to A.6.4 [12] by deriving it from the corresponding characteristic value $R_{k}$ determined by testing, using:

$$
M_{c, R d}^{\text {Test }}=\eta_{s y s} \frac{R_{k}}{\gamma_{m}}=90.94 \mathrm{kNm},
$$

where $\gamma_{m}$ is the partial factor for resistance; (1.0 for buildings). $\eta_{s y s}$ is a conversion factor for differences in behavior under test conditions and service conditions (may be taken as 1.0$)$.

The results (Table 4) show clearly that EC 1993 result and adjusted test result according to EC 1993 are almost the same; however, these two values could be somewhat conservative with reference to the numerical model result of RHFB. Moreover, employing amplitude value according to EC recommendation gives higher resistance, which could be because of this value, has been developed for hot rolled sections; thus, EC recommendation should be improved to use higher imperfection value in case of RHFBs.

Table 4. Comparison of design values

\begin{tabular}{lc}
\hline & $\begin{array}{c}\text { Design moment value } \\
(\mathrm{kNm})\end{array}$ \\
\hline Calculated from Eurocode $M_{\mathrm{c}, \mathrm{Rd}}^{\mathrm{Ec}}$ & 91.90 \\
Obtained from test results & 90.94 \\
$\quad$ adjustment $M_{\mathrm{c}, \mathrm{Rd}}^{\mathrm{Test}}$ & \\
Obtained from numerical model & 9,827 \\
$\quad$ with nominal material grades & \\
$M_{\mathrm{c}, \mathrm{Rd}}^{\mathrm{FEM}}$ & \\
\hline
\end{tabular}

\subsection{Cross section development for bending}

In this subsection the cross section was improved by adding two intermediate stiffeners, one in the middle of the upper part of the top flange and another one in the middle of the lower part of the bottom flange as it is shown in Fig. 5. This type of stiffening solution; proposed to refrain local buckling, is a feature of the product and it could be considered as an optimized section based on [2]. It is useful to mention here that this kind of section is always found supported by sheathing in construction conditions, thus any kind of global buckling is avoided. Both numerical and theoretical studies of the new cross section were conducted.

A shell finite element model for the optimized cross section has been developed by using nominal dimensions and material grades and $10 \times 10 \mathrm{~mm}$ dimensions of intermediate stiffeners, where $x \times x$ symbol is used to determine the stiffener size as it is shown in Fig. 5.

The maximum imperfection amplitude was taken here according to Eurocode $\operatorname{imp}=a / 200$, where $a$ is equal to $(150 / 2-10=65 \mathrm{~mm})$.

Figure 6 shows a comparison of bending momentdisplacement curves between the original cross section and the improved one. The figure shows a small improvement (4.4\%) between the two curves. Moreover, the failure mode of the top compressed flange (Fig. 7) was much better in comparison with the original one, where no local buckling

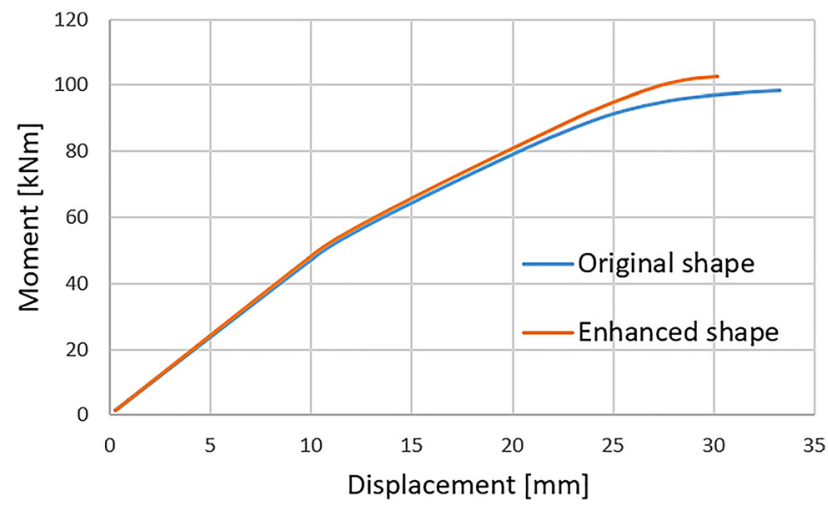

Fig. 6. Comparison of bending moment-displacement curves for the original and enhanced cross section by intermediate stiffeners in the flanges

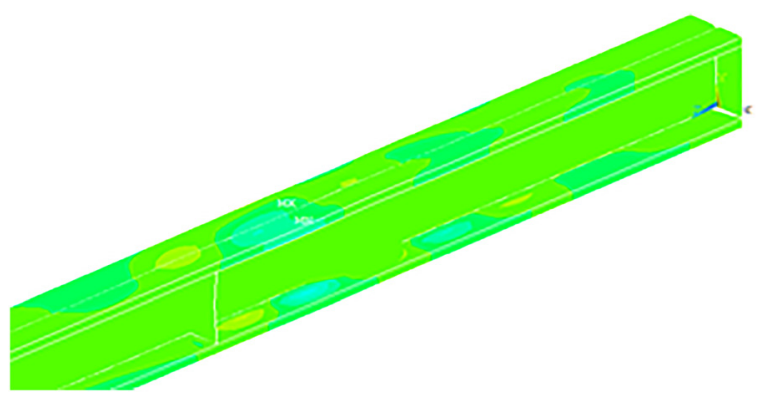

Fig. 7. Lowest local buckling mode shape of the compression flange of improved cross section by intermediate stiffeners in the flanges 
Table 5. Comparison of bending design values of original and improved shape

\begin{tabular}{lcc}
\hline Design moment value $(\mathrm{kNm})$ & $\begin{array}{c}\text { Original } \\
\text { section }\end{array}$ & $\begin{array}{c}\text { Optimized } \\
\text { section }\end{array}$ \\
\hline Numerical modeling & $M_{c, R d}^{F E M}=98.27$ & $M_{c, R d}^{F, F E M}=102.60$ \\
Calculation according to EN & $M_{c, R d}^{E c}=91.90$ & $M_{c, R d}^{F, E c}=95.36$ \\
$1993-1-3[12]$ & & \\
\hline
\end{tabular}

wave's distribution was observed, but only few small local dents.

On the other hand, the design moment capacity of the improved section was determined by following the steps of Plane elements with intermediate stiffeners calculation [12], and by using nominal geometry and material grades.

The results (Table 5) show a small improvement between the two sections, which is $4.4 \%$ according to the numerical results and $3.77 \%$ according to EC based calculation. Eventually, it might be seen that there is no significant improvement regarding the bending design value.

\section{CROSS-SECTION ANALYSIS AND DEVELOPMENT FOR SHEAR FORCE}

Nowadays, both hot rolled and cold formed sections are used as bracing and shear panels. Thus, the investigation of shear capacity and buckling is very important especially for seismic studies $[14,15]$. Consequently, the shear design capacity was studied in this section.

\subsection{Original section}

The shear design capacity was calculated according to [12]. Namely, two cases were taken into consideration. The first one

1. is considering the web resistance only; while the second one

2. is considering the web and the vertical part of flanges resistances as well.

In order to observe the real shear behavior, a cantilever of $0.50 \mathrm{~m}$ span was modeled. The suggested numerical model is very close to pure shear. In fact, it is not easy to model a pure shear case, but since bending moment is not dominant in this model and according to the interaction curve of bending and shear in Eurocode, the proposed model can be considered as a pure shear case with good approximation. The load was applied by imposing two increasing concentrated loads to the top nodes of the web stiffener located at right end (Fig. 8). A local imperfection was introduced according to Fig. 8. Actually, the buckling mode (Fig. 8) obtained from buckling analysis can be used to predict the ultimate shear load, since the cross section, Boundary conditions and loads are symmetric. The amplitude of the imperfection was selected according to Eurocode [14] $a / 200$, in this case $a$ is equal to the web depth.
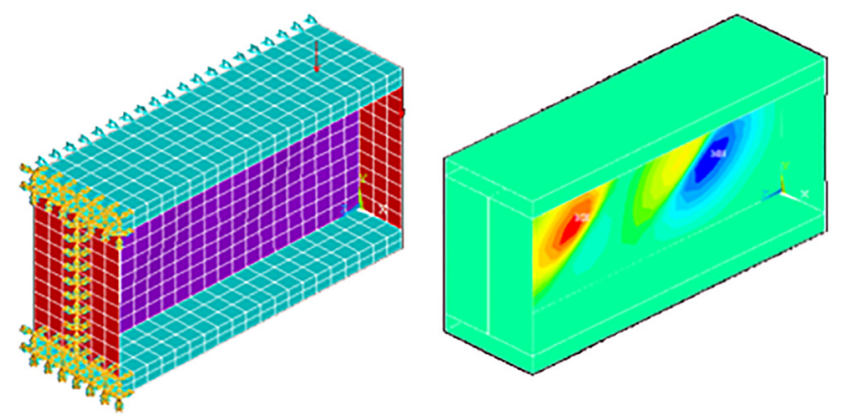

Fig. 8. Left: Cantilever model, right: lowest local buckling mode of the web

\subsection{Cross section development for shear}

Here an improved cross section was proposed by adding one longitudinal stiffener; size $20 \times 20 \mathrm{~mm}$, in the middle of the web plate as shown in Fig. 9. The tension bands distribution in the web has been highly affected by the suggested modification. Theoretical design shear value was calculated based on [12]. The same numerical model that was introduced in subsection 4.1 was used here for the modified section. In fact, the expected buckling mode represented by tension bands development; which is carried by the web, was not detected. However, the seventh buckling mode (Fig. 9) was the closest one to the expected failure mechanism. As mentioned in the previous section, the buckling mode (Fig. 9) obtained from buckling analysis can predict the ultimate shear load with good approximation, since the cross section, boundary conditions and loads are symmetric.

The results (Table 6) of the original section show that there is a significant difference in numerical and theoretical
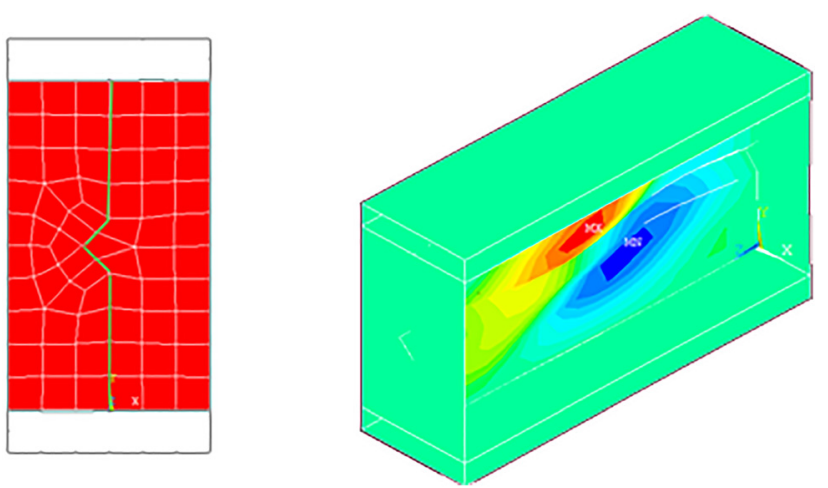

Fig. 9. Improved cross section by intermediate stiffener in the web, left: shape; right: shear buckling mode of the web

Table 6. Comparison of shear design values of original and improved shapeby intermediate stiffener in the web

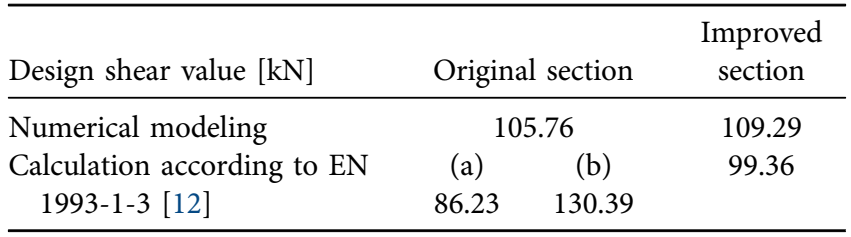


outcomes. In particular, the numerical value is higher than the EC based value by $22.65 \%$ in case (a). In contrast, it is smaller than EC based value by $23.29 \%$ in case (b). On the other hand, the design shear value of numerical analysis of the modified section is better than that of the original section by $3.34 \%$, while it is better by $15.22 \%$ according to EC based calculation (case (a)). In fact, the use of larger stiffener size will not give advantages because the relative web slenderness is already in the lowest range; hence, no increasing in the shear buckling strength will be achieved. Accordingly, the results revealed that EN design rules of determining the shear capacity of RHFBs should be edited since their results did not match with the numerical ones. Additionally, the utilization of intermediate stiffener in the web seems to be unprofitable and hence, only the original section and improved section with intermediate stiffeners in flanges will be used for the study of shear force and bending moment interaction in the next section.

\section{CROSS-SECTION ANALYSIS FOR THE INTERACTION OF SHEAR FORCE AND BENDING MOMENT}

Resistance curves for shear and bending interaction were drawn according to EN 1993-1-3 specifications [12] for both original profile and improved cross section by intermediate stiffeners in the flanges. Moreover, numerical simulation for both sections was conducted by performing several finite element models. Indeed, the developed models were the same as the cantilever model which was carried out through the studying of shear case, but different cantilever lengths were implemented to define resistances for various bending and shear ratios. Imperfections for both shear and bending were introduced in order to investigate the beam behavior under shear and bending interaction. Figure 10 shows two continuous curves drawn according to Eurocode limitations. Likewise, scattered points; obtained from numerical models, were plotted. In the figure, $V_{w, R}$ and $M_{y, R}$ are the design shear resistance of the web and the design moment

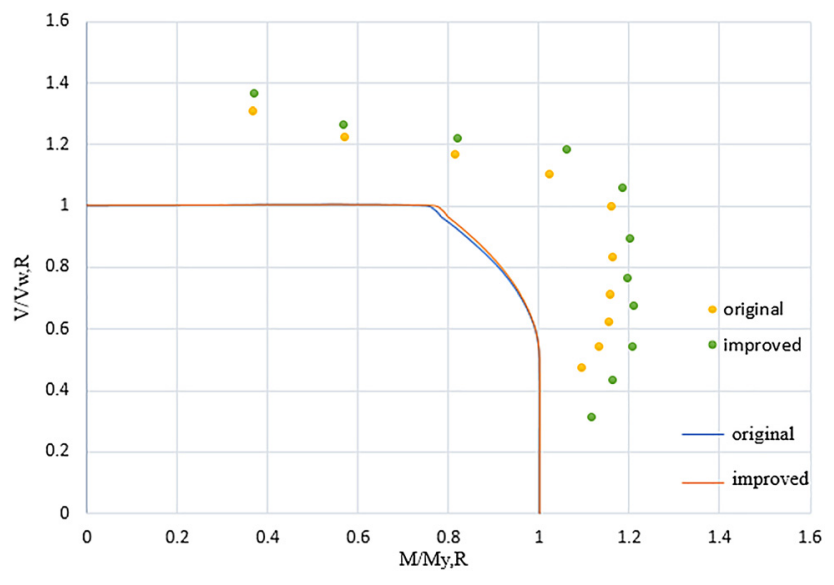

Fig. 10. Shear force and bending moment interaction curves resistance of the cross-section respectively. As a result, the numerical outcomes were slightly higher than the theoretical ones.

\section{CONCLUSIONS}

To conclude this paper, several consequences could be predicted as follow:

1. Based on the comparison between the numerical simulation; verified by experimental data tests, and Eurocode, using higher local imperfection amplitude by $17 \%$ approximately in EC might give better result in case of rectangular hollow flange sections.

2. Design rules to determine bending and bending and shear interaction capacities of RHFBs based on Eurocode tend to be somewhat conservative.

3. The improved section by using intermediate stiffeners in flanges in bending case increased the moment resistance of the original rectangular hollow flange profile by $4.4 \%$.

4. In shear case, the results showed that current standard rules are not quite accurate to determine the design shear capacity of RHFBs, and that might be due that the design rules assume that only the web carries shear force while the examined profile gives extra support in shear case through its flanges.

5. It can also be observed that the use of intermediate stiffener in the center of the web has no significant effect on shear resistance for the studied case.

At last, recommendations for future research works might be conducting more studies to develop the current design rules in Eurocode, and to determine the effect of different intermediate stiffener sizes and shapes for RHFBs.

\section{REFERENCES}

[1] H.-X. Wan and M. Mahendran, "Bending and torsion of hollow flange channel beams," Eng. Struct., vol. 84, pp. 300-312, 2015.

[2] N. Tondini and A. Morbioli, "Cross-sectional flexuralcapacityofcold-formedlaterally-restrained steel rectangular hollow flange beams," Thin-Walled Struct., vol. 95, pp. 196-207, 2015.

[3] K. S. Wanniarachchia and M. Mahendran, "Experimental study of the section moment capacity of cold-formed and screw-fastened rectangular hollow flange beams," Thin-Walled Struct., vol. 119, pp. 499-509, 2017.

[4] N. S. Trahair and J. J. Papangelis, "Lateral-distortional buckling of beams with hollow flanges and folded plate," Eng. Struct., vol. 163, pp. 71-76, 2018.

[5] M. Karunakaran and M. H. Santhi, "Investigation on cold formed steel rectangular hollow flanged ' $\mathrm{z}$ ' beam section," Int. J. Recent Res. Sci. Eng. Technol., vol. 2, no. 10, pp. 1-6, 2014.

[6] S. Jeyaragan and M. Mahendran, "Experimental investigation of the new built-up Litesteel beams," in 5th International Conference on Thin-walled Structures, Brisbane, Australia, Jun. 18-20, 2008, 2008, pp. 1-10. 
[7] S. Jeyaragan and M. Mahendran, "Strength improvement methods for back to back Litesteel beams," in 4th International Conference on Steel \& Composite Structures, Sydney, Australia, Jul. 21-23, 2010, 2010, pp. 1-8.

[8] P. Avery and M. Mahendran, "Finite element analysis of hollow flange beams with web stiffeners," in Thirteenth International Specialty Conference on Cold-Formed Steel Structures, St. Louis, Missouri USA, Oct. 17-18, 1996, 1996, pp. 224-241.

[9] M. M. Joy and J. Mathew, "Analysis of rivet fastened rectangular hollow flange channel beams," Int. Res. J. Eng. Technol., vol. 04, no. 4, pp. 3505-3510, 2017.

[10] ANSYS, Documentation for ANSYS-Release 19.2, Copyright SAS IP, Inc, 2018.
[11] B. Schafer and T. P. Peköz, "Computational modeling of coldformed steel: characterizing geometric imperfections and residual stresses," J. Constr. Steel Res., vol. 47, no. 3, pp. 193-210, 1998.

[12] EN 1993-1-3, Eurocode 3, Design of Steel Structures, Part 1-3: General Rules, Supplementary Rules for Cold-formed Members and Sheeting, Bruxelles, CEN, 2006.

[13] EN 1993-1-5, Eurocode 3, Design of Steel Structures, Part 1-5: Plated Structural Elements, Bruxelles, CEN, 2006.

[14] G. Brando, "Experimental tests on bracing type pure aluminum shear panels," Pollack Period., vol. 2, no. 3, pp. 73-84, 2007.

[15] A. Formisano, "Experimental-numerical investigation on stiffened aluminum shear panels," Pollack Period., vol. 1, no. 3, pp. 57-77, 2006. 